\title{
DIRECT VECTOR CONTROL WITH FUZZY CURRENT CONTROLLER FOR THREE-PHASE INDUCTION MOTOR
}

\author{
José L. Azcue-Puma*, Alfeu J. Sguarezi Filho** and Ernesto Ruppert* \\ DSCE/FEEC/UNICAMP* CECS/UFABC** \\ Campinas - SP - Brazil* Santo André - SP - Brazil** \\ azcue@ieee.org, alfeu.sguarezi@ufabc.edu.br, ruppert@fee.unicamp.br
}

\begin{abstract}
This article proposes a Direct Vector Control (DVC) method with a Fuzzy Logic Current Controller (FLCC) for three-phase induction motor. The conventional DVC method has two PI current controllers. With the aim to reduce the quantity of these controllers, we propose a single FLCC to substitute both PI controllers. The FLCC calculates the quadrature components of the stator voltage vector which are necessary to maintain the load. The rule base for the proposed controller is defined as a function of the stator current error components, and FLCC utilizes trapezoidal and triangular membership functions for the fuzzification of its inputs. The switching frequency is constant with the space vector modulation technique used in the DVC method. The performance of the proposed FLCC controller is analyzed through several tests such as: trapezoidal and triangular speed profile, step change in speed and step change in load with constant speed. The simulation and experimental results show that the proposed FLCC ensures decoupling current control and low current ripple, validating the proposed controller.
\end{abstract}

Keywords - Direct Vector Control, Fuzzy Controllers, Induction Motor.

\section{INTRODUCTION}

The three-phase induction motors (IM) are widely used in industrial applications because of their simple and robust structure, higher torque-to-weight ratio, higher reliability and ability to operate in dangerous environment. However, because of the coupling between torque and flux, unlike dc motors, their control is a challenging task. A popular method to control the high performance electric drive for IM is the field oriented control (FOC) [1]. FOC leads to decoupling of stator current into torque and flux, producing components that give independent control over the motor torque while maintaining a constant flux that enables an accurate and precise IM control.

Fuzzy logic offers an alternative technique to the design of such control systems making decisions based on human expertise, thus avoiding complex calculations. The Fuzzy Logic Controller (FLC) to be investigated in this article is the Sugeno type [2], although there are other types, as, the Mamdani [3] and the Yamakawa [4].

Fuzzy controllers have proved to be powerful in the power electronics area and in the control of electric machines as shown in various articles in the literature, e.g., [5] proposes an

Manuscript received on 24/09/2012 and revised on 11/01/2013. Second review concluded on 05/04/2013 and acceptance for publication issued on 07/04/2013, upon recommendation of Regular Section Editor Henrique A. C. Braga. adaptive fuzzy system estimator applied to speed control in a three-phase induction motor sensorless drive and [6] proposes a DSP-based fuzzy system for scalar control of induction motor. Furthermore, in [7] and [8], a FLC is implemented for speed control using the FOC technique. It provides better motor control with high dynamic performance. In [9], another fuzzy speed controller is compared with conventional PI controller, showing that this controller has superior performance under varying operating conditions, such as step change in speed and torque reference. Similarly, [10] proposes the fuzzy speed controller, but this controller is applied in the indirect field-oriented control (IFOC) method. This method was compared with two speed control techniques, scalar control and conventional indirect field oriented control, showing its superiority. In [11], a neuro-fuzzy controller for speed control of an IM is proposed, thus assuring excellent performance, but this method is also applied to the IFOC method.

Radwan et al. [12] propose the FLC with less computational process with aim to facilitate its real-time implementation; the FLC parameters were tuned by genetic algorithm resulting in a robust controller for high performance industrial drive applications, and [13] also applies a genetic algorithm to optimize the fuzzy speed controller design with indirect FOC scheme. Moreover, more controllers that work with selforganizing self-tuning fuzzy logic controller, and a model reference adaptive speed control are presented in [14] and [15], respectively.

In [16], the effectiveness of the self-tuned FLC in the current control loop of IM drives based on FOC is investigates; its experimental results show better performance in comparison with the optimal PI current controllers. Although, this FLC has various parameters for tuning.

The majority of the articles mentioned above are focused on speed control, even when the current control plays an important role within the DVC method. Unlike the previously mentioned works, this article proposes a single FLCC controller in order to replace both PI current controllers used in the conventional DVC method. The FLCC calculates the quadrature components of the stator voltage vector represented in the rotor-flux-oriented reference frame. The inputs of the FLCC are the direct-axis stator current error and the quadrature-axis stator current error. The rule base for the proposed FLCC is defined as a function of its inputs. The membership functions used for the fuzzification of the FLCC inputs have trapezoidal and triangular shapes because these functions are suitable for real-time operations [17]. Therefore, the first output, which is the direct-axis component of the stator voltage vector, is represented as a linear combination of the FLCC inputs. However, the quadrature-axis component 
of the stator voltage is similarly represented as a linear combination used in the first output but with the same parameters with interchanged order, being it not necessary other different parameter values for this output. This is the major contribution of this article, because it only need two parameters for both outputs in each rule, thus reducing the computational cost of its implementation. The simulation and experimental results show that the proposed FLCC for the DVC method has a good performance when tested under various operating conditions, therefore validating the proposed method.

This article is organized as follows. In section II, we give the theoretical background for the dynamical equations of the three-phase IM and the direct vector control. In section III, we analyze the DVC method with the FLCC, and in section IV the proposed FLCC is described in details, mentioning different aspects of its design. Section $\mathrm{V}$ presents the simulation and experimental results, and in Section VI the conclusions are given.

\section{THEORETICAL BACKGROUND}

A. Dynamical Equations of the Three-Phase Induction Motor

By the definition of the flux, current and voltage space vectors, the dynamical equations of the three-phase IM in stationary reference frame can be put into the following mathematical form [18]:

$$
\begin{aligned}
\vec{u}_{s} & =R_{s} \vec{i}_{s}+\frac{d \vec{\psi}_{s}}{d t} \\
0 & =R_{r} \vec{i}_{r}+\frac{d \vec{\psi}_{r}}{d t}-j \omega_{r} \vec{\psi}_{r} \\
\vec{\psi}_{s} & =L_{s} \vec{i}_{s}+L_{m} \vec{i}_{r} \\
\vec{\psi}_{r} & =L_{r} \vec{i}_{r}+L_{m} \vec{i}_{s}
\end{aligned}
$$

Where $\vec{u}_{s}$ is the stator voltage space vector, $\vec{i}_{s}$ and $\vec{i}_{r}$ are the stator and rotor current space vectors, respectively, $\vec{\psi}_{s}$ and $\vec{\psi}_{r}$ are the stator and rotor flux space vectors, respectively, $\omega_{r}$ is the rotor angular speed, $R_{s}$ and $R_{r}$ are the stator and rotor resistances, respectively, $L_{s}, L_{r}$ and $L_{m}$ are the stator, rotor and mutual inductances, respectively.

The electromagnetic torque is expressed in terms of the cross product of the stator and rotor flux space vector.

$$
\begin{aligned}
t_{e} & =\frac{3}{2} P \frac{L_{m}}{L_{r}} \vec{\psi}_{r} \times \vec{i}_{s} \\
t_{e} & =\frac{3}{2} P \frac{L_{m}}{L_{r}}\left(\psi_{d r} i_{q s}-\psi_{q r} i_{d s}\right)
\end{aligned}
$$

Where $P$ is a number of pole pairs, $\psi_{d r}$ and $\psi_{q r}$ are the quadrature components of the rotor flux, respectively, and $i_{d s}$ and $i_{q s}$ are the quadrature components of the stator current, respectively.

\section{B. Direct Vector Control}

In rotor-flux-oriented reference frame, the quadrature component of the rotor flux disappears and a physically easily comprehensible representation of the relations between torque, flux and current components are obtained. This representation can be expressed in the following formula.

$$
\begin{gathered}
\psi_{d r}=\frac{L_{m}}{1+s T_{r}} i_{d s} \\
t_{e}=\frac{3}{2} P \frac{L_{m}}{L_{r}} \psi_{d r} i_{q s}
\end{gathered}
$$

Considering that $\psi_{d r}=\psi_{\mathbf{r}}$, we can rewrite this equation as:

$$
t_{e}=\frac{3}{2} P \frac{L_{m}}{L_{r}} \psi_{\mathbf{r}} i_{q s}
$$

Where $s$ is a Laplace operator, $\psi_{\mathbf{r}}$ is the rotor flux module, and $T_{r}=L_{r} / R_{r}$ is a rotor time constant.

Equation (7) shows that the component $i_{d s}$ of the stator current can be used as a control quantity for the rotor flux $\psi_{d r}$. If the rotor flux can be kept constant with the help of $i_{d s}$, then the cross component $i_{q s}$ plays the role of a control variable for the torque $t_{e}$ [19].

\section{THE PROPOSED DIRECT VECTOR CONTROL METHOD}

In Figure 1 we show the block diagram of the proposed direct vector control (DVC) method; it only needs to sense the DC link voltage and the two phases of the stator currents of the three-phase IM to calculate the stator voltage and to estimate the rotor flux. In the DVC method, the FLCC takes as inputs the direct-axis component of the stator current error $\left(E_{i_{d s}}\right)$ and the quadrature-axis component of the stator current error $\left(E_{i_{q s}}\right)$, and as outputs the quadrature components of the stator voltage necessary to maintain the speed and load. These outputs are represented in the rotor-flux-oriented reference frame. Details about the FLCC are going to be presented in the next section.

\section{A. Stator Voltage Calculation}

The stator voltage calculation utilizes the DC link voltage $V_{d c}$, and the inverter switch state $\left(S_{a}, S_{b}, S_{c}\right)$ of the three leg two level inverter. The stator voltage vector $\vec{u}_{s}$ is determined as in [20]:

$$
\vec{u}_{s}=\frac{2}{3}\left[\left(S_{a}-\frac{S_{b}+S_{c}}{2}\right)+j \frac{\sqrt{3}}{2}\left(S_{b}-S_{c}\right)\right] V_{d c}
$$

\section{B. Rotor Flux Estimation}

To estimate the rotor flux, first we need to estimate the stator flux. The stator flux estimation depends on the back electromotive force (emf):

$$
\begin{aligned}
& \vec{\psi}_{s}=\int\left(\vec{u}_{s}-R_{s} \cdot \vec{i}_{s}\right) d t \\
& \vec{\psi}_{s}=\int(\mathrm{emf}) d t
\end{aligned}
$$

when the stator flux is calculate with equation (11) it has problems associated with a pure integrator. With the aim to solve this problem an integrator is used with an adaptive 


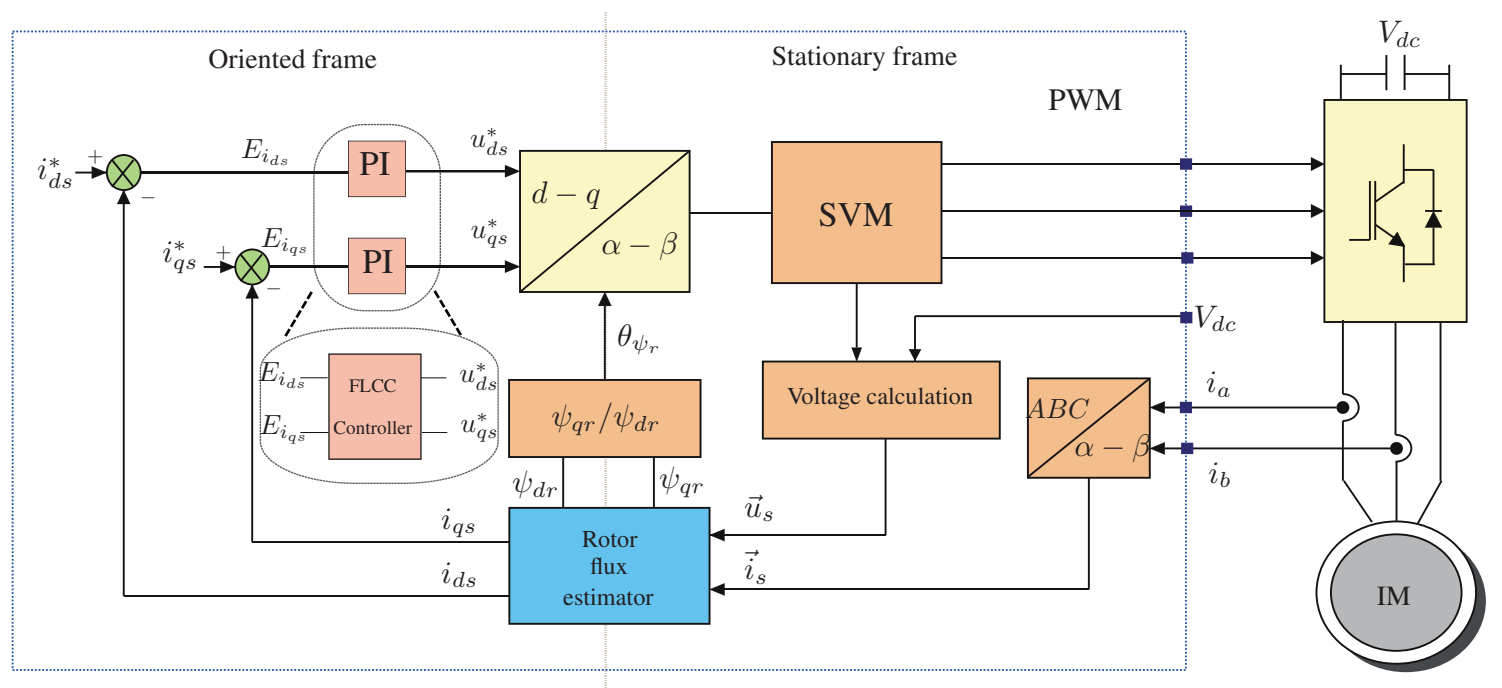

Fig. 1. Direct Vector Control (DVC) method with Fuzzy Logic Current Controller (FLCC).

compensation method proposed in [21] [22]. This method can be used to accurately estimate the motor flux including its magnitude and phase angle over a wide speed range.

Figure 2 shows a block diagram of this method. The main idea of this method is the fact that the motor flux is orthogonal to its back emf. The quadrature detector detects if the orthogonality between the estimated flux and bemf is maintained. A PI controller is used to generate a compensation level:

$$
\psi_{\mathrm{cmp}}=\left(k_{p}+\frac{k_{i}}{s}\right) \frac{\psi_{q s} \cdot \mathrm{emf}_{q}+\psi_{d s} \cdot \mathrm{emf}_{d}}{\left|\vec{\psi}_{s}\right|}
$$

where $k_{p}$ and $k_{i}$ are the gains of the PI controller. The magnitude of $\psi_{\mathrm{cmp}}$ is governed by equation (12). The operating principle of this method is explained by using a vector diagram shown in Figure 3. The estimated stator flux vector is a sum of two vectors, a feedforward vector $\vec{\psi}_{1}$, which is the output of the Low Pass (LP) filters $\left(\psi_{d 1}\right.$ and $\left.\psi_{q 1}\right)$ and a feedback vector $\vec{\psi}_{2}$, which is composed of $\psi_{d 2}$ and $\psi_{q 2}$. Ideally, the flux vector $\vec{\psi}_{s}$ should be orthogonal to the emf, and the output of the quadrature detector is zero. When an initial value or dc drift is introduced to the integrator, the above orthogonal relation is lost, and the phase angle between the

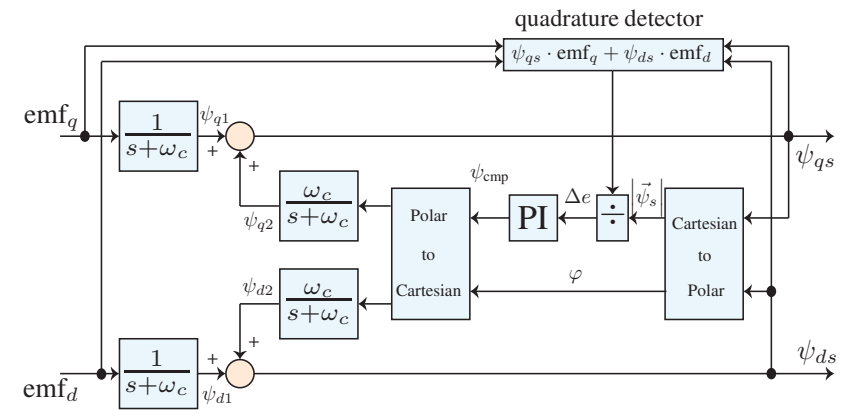

Fig. 2. Block diagram of the adaptive compensation method.

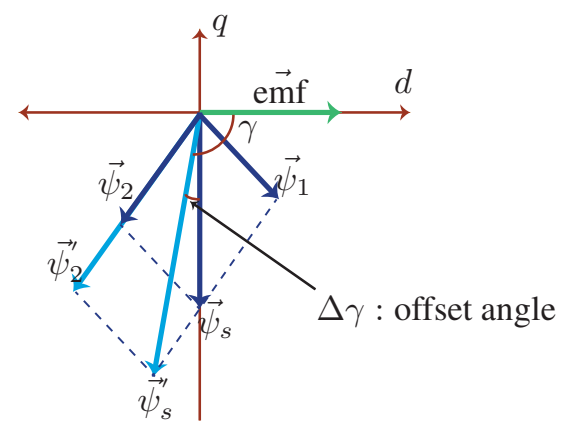

Fig. 3. Vector diagram showing the emf and flux linkage relationship.

flux and emf vectors is no longer $90^{\circ}$, which yields an error signal defined by

$$
\begin{aligned}
\Delta \vec{e} & =\vec{\psi}_{s} \cdot \mathrm{emf} /\left|\vec{\psi}_{s}\right|=\left(\psi_{q s} \cdot \mathrm{emf}_{q}+\psi_{d s} \cdot \mathrm{emf}_{d}\right) /\left|\vec{\psi}_{s}\right| \\
\Delta \vec{e} & =|\mathrm{emf}| \cos (\gamma)
\end{aligned}
$$

Assuming that the magnitude of the feedback vector $\vec{\psi}_{2}$ is increased to $\vec{\psi}_{2}^{\prime}$ as shown in Figure 3 due to a dc offset or initial value problem, the phase angle $\gamma$ will be greater than $90^{\circ}$. The quadrature detector will generate a negative error signal. The output of the PI regulator $\psi_{\mathrm{cmp}}$ is reduced and so is the feedback vector. As a result, the flux vector $\vec{\psi}_{s}^{\prime}$ moves toward the original position of $90^{\circ}$ until the orthogonal relationship between $\vec{\psi}_{s}$ and emf is reestablished. If $\gamma$ is less than $90^{\circ}$ for some reason, an opposite process will occur, which brings $\gamma$ back to $90^{\circ}$. Therefore, the modified integrator with the adaptive control can adjust the flux compensation level $\psi_{\mathrm{cmp}}$ automatically to an optimal value such that the initial value and dc drift problems are essentially eliminated.

Remember that $\vec{\psi}_{s}=\psi_{d s}+j \psi_{q s}$, and with it the rotor flux $\vec{\psi}_{r}$ is calculated through motor model, in the stationary reference frame, as 


$$
\vec{\psi}_{r}=\frac{L_{r}}{L_{m}} \vec{\psi}_{s}-\frac{L_{s} L_{r}-L_{m}^{2}}{L_{m}} \vec{i}_{s}
$$

The rotor flux angle $\theta_{\psi_{r}}$ necessary to oriented the system is obtained by

$$
\theta_{\psi_{r}}=\tan \left(\frac{\psi_{q r}}{\psi_{d r}}\right)
$$

\section{FUZZY LOGIC CURRENT CONTROLLER (FLCC)}

The FLCC proposed in this article is the Sugeno type [2]. The FLCC is based on a suitable set of fuzzy rules, carried out from both the knowledge of the experimental behavior and the internal structure of the controlled system. In order to design a FLCC, the following steps must be performed:

1. Development of a suitable rule set.

2. Selection of input/output variables and their quantization in fuzzy sets.

3. Definition of membership functions to be associated with the input variables.

4. Selection of the defuzzification technique.

The FLCC [Figure 4] takes as inputs the direct-axis component of the stator current error $E_{i_{d s}}$ and the quadratureaxis component of the stator current error $E_{i_{q s}}$, and as outputs the quadrature components of the stator voltage vector. The output stator voltage is represented in the rotor-flux-oriented reference frame. The first output $\left(u_{d s}^{*}\right)$ is a linear combination of the inputs; similarly, the second output $\left(u_{q s}^{*}\right)$ takes the similar linear combination used in the first output but with interchanged parameter order as is detailed in the fuzzy rule base subsection.

\section{A. Membership Functions}

The Membership Functions (MFs) of the FLCC inputs are shown in Figure 5 and Figure 6; these MFs are used in the fuzzification process to convert numerical variables into fuzzy variables. The shape and the universe of discourse were adjusted through the simulation process using the trial and error method.

The universe of discourse for the input $E_{i_{d s}}$ is defined in the closed interval $[-0.5,0.5]$. The extreme MFs have trapezoidal shapes but the middle MF takes triangular shape as shown in Figure 5. However, the universe of discourse for the input $E_{i_{q s}}$ is defined in the closed interval $[-10,10]$ as is shown in Figure 6. The shapes of these MFs are similar to the first

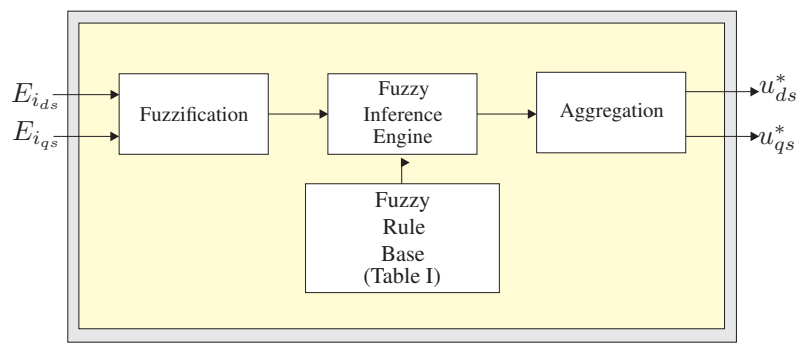

Fig. 4. The structure of a fuzzy logic current controller.

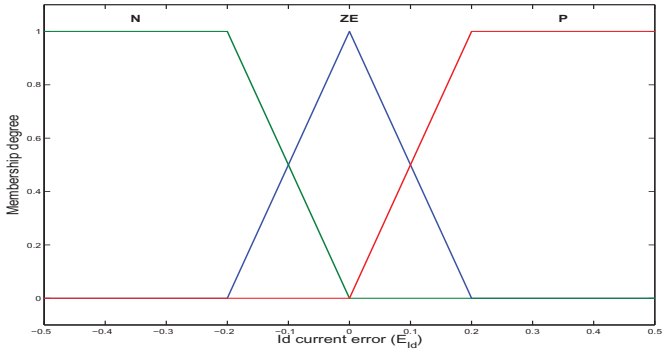

Fig. 5. Membership function for the direct-axis component of the stator current error $E_{i_{d s}}$.

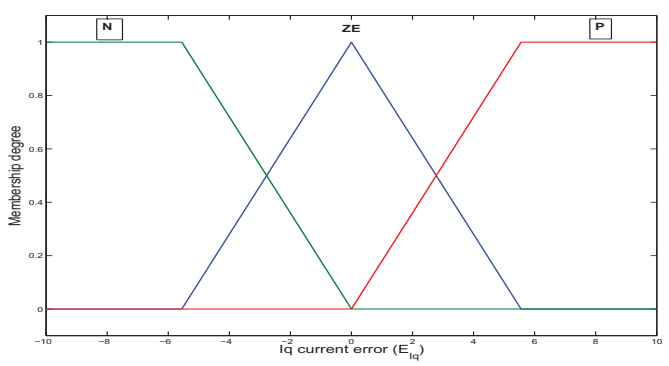

Fig. 6. Membership function for the quadrature-axis component of the stator current error $E_{i_{q s}}$.

input. For both inputs the linguistic labels are N (Negative), Ze (Zero) and P (Positive).

\section{B. The Fuzzy Rule Base}

A set of rules for the direct component of the stator voltage $u_{d s}^{*}$ are defined by the rules of the following form:

$$
\begin{gathered}
R_{V_{d s}}^{1}: \quad \text { if } E_{i_{d s}} \text { is } \mathrm{N} \text { and } E_{i_{q s}} \text { is } \mathrm{N} \text { then } \\
V_{d s}^{R_{1}}=a \cdot E_{i_{d s}}+b \cdot E_{i_{q s}}
\end{gathered}
$$

However, the set of rules for the quadrature component of the stator voltage $u_{q s}^{*}$ are defined by the rules of the following form:

$$
\begin{gathered}
R_{V_{q s}}^{1}: \quad \text { if } E_{i_{d s}} \text { is } \mathrm{N} \text { and } E_{i_{q s}} \text { is } \mathrm{N} \text { then } \\
V_{q s}^{R_{1}}=-b \cdot E_{i_{d s}}+a \cdot E_{i_{q s}}
\end{gathered}
$$

The $\mathbf{a}$ and $\mathbf{b}$ parameters of the first-order polynomial function typically present in the consequent part of the firs-order Takagi-Sugeno fuzzy controllers. Observe that these parameters for $V_{d s}^{R_{1}}$ and $V_{q s}^{R_{1}}$ are the same but with interchanged order, being it not necessary other different parameters for each one, as they are repeated for all the rules. For instance, when the consequent part of the rule is a real number, we have a zero-order controller, but if the consequent is a linear combination we have a first-order controller [23]. The complete rule base to calculate $u_{d s}^{*}$ and $u_{q s}^{*}$ is shown in Table I, where $(a=5 ; b=0.1),(c=6.5 ; d=0.2),(e=8 ; f=0.1)$. 
TABLE I

Fuzzy rules for computation of $u_{d s}^{*}$ and $u_{q s}^{*}$.

\begin{tabular}{clll}
\hline$E_{i_{d s}} / E_{i_{q s}}$ & $\mathbf{N}$ & $\mathbf{Z E}$ & $\mathbf{P}$ \\
\hline $\mathbf{N}$ & $V_{d s}^{R_{1}}=a \cdot E_{i_{d s}}+b \cdot E_{i_{q s}}$ & $V_{d s}^{R_{2}}=a \cdot E_{i_{d s}}+b \cdot E_{i_{q s}}$ & $V_{d s}^{R_{3}}=c \cdot E_{i_{d s}}+d \cdot E_{i_{q s}}$ \\
& $V_{q s}^{R_{1}}=-b \cdot E_{i_{d s}}+a \cdot E_{i_{q s}}$ & $V_{q s}^{R_{2}}=-b \cdot E_{i_{d s}}+a \cdot E_{i_{q s}}$ & $V_{q s}^{R}=-d \cdot E_{i_{d s}}+c \cdot E_{i_{q s}}$ \\
\hline $\mathbf{Z E}$ & $V_{d s}^{R_{4}}=a \cdot E_{i_{d s}}+b \cdot E_{i_{q s}}$ & $V_{d s}^{R_{5}}=c \cdot E_{i_{d s}}+d \cdot E_{i_{q s}}$ & $V_{d s}^{R_{6}}=e \cdot E_{i_{d s}}+f \cdot E_{i_{q s}}$ \\
& $V_{q s}^{R_{4}}=-b \cdot E_{i_{d s}}+a \cdot E_{i_{q s}}$ & $V_{q s}^{R}=-d \cdot E_{i_{d s}}+c \cdot E_{i_{q s}}$ & $V_{q s}^{R_{6}}=-f \cdot E_{i_{d s}}+e \cdot E_{i_{q s}}$ \\
\hline \multirow{2}{*}{$\mathbf{P}$} & $V_{d s}^{R_{7}}=c \cdot E_{i_{d s}}+d \cdot E_{i_{q s}}$ & $V_{d s}^{R_{8}}=e \cdot E_{i_{d s}}+f \cdot E_{i_{q s}}$ & $V_{d s}^{R}=e \cdot E_{i_{d s}}+f \cdot E_{i_{q s}}$ \\
& $V_{q s}^{R_{7}}=-d \cdot E_{i_{d s}}+c \cdot E_{i_{q s}}$ & $V_{q s}^{R_{8}}=-f \cdot E_{i_{d s}}+e \cdot E_{i_{q s}}$ & $V_{q s}^{R_{9}}=-f \cdot E_{i_{d s}}+e \cdot E_{i_{q s}}$ \\
\hline
\end{tabular}

\section{Inference Method}

In general, operators on fuzzy sets use triangular norms, which may be divided into T-norms (AND operators) and S-norms (OR operators) [24] [25]. T-norms perform an intersection operation on fuzzy sets and have a particular importance in fuzzy logic control. T-norm is usually denoted as $\mathrm{T}(\mathrm{a}, \mathrm{b})$. The T-norms used in our FLCC is the product defined as:

$$
\begin{aligned}
& \mu^{R_{i}}=T\left(\mu_{E_{i d s}}^{i}, \mu_{E_{i_{q s}}}^{i}\right)=\mu_{E_{i_{d s}}}^{i} \cdot \mu_{E_{i_{q s}}}^{i} \\
& \text { for } i=1, \ldots, n ; n=9
\end{aligned}
$$

where $\mu_{E_{i_{d s}}}^{i}$ and $\mu_{E_{i_{q} s}}^{i}$ are MFs degrees of the first and second FLCC inputs, respectively, and $\mu^{R_{i}}$ is the truth value of the preposition.

\section{Aggregation}

The final output value $u_{d s}^{*}$ inferred from $n=9$ implications is aggregated as the average of all $V_{d s}^{R_{i}}$ with the weights $\mu^{R_{i}}$ :

$$
u_{d s}^{*}=\frac{\sum_{i=1}^{n} \mu^{R_{i}} V_{d s}^{R_{i}}}{\sum_{i=1}^{n} V_{d s}^{R_{i}}}
$$

and the final output value $u_{q s}^{*}$ inferred from $n=9$ implications is aggregated as the average of all $V_{q s}^{R_{i}}$ with the weights $\mu^{R_{i}}$ :

$$
u_{q s}^{*}=\frac{\sum_{i=1}^{n} \mu^{R_{i}} V_{q s}^{R_{i}}}{\sum_{i=1}^{n} V_{q s}^{R_{i}}}
$$

In our FLCC, that is Sugeno type, it is not necessary the defuzzification interface [26] [27], as its common use in Mamdani's [3] type controllers. This is so because, in TakagiSugeno fuzzy controllers, each rule is already crisp and the total result is determined by the weighted sum of each rule, as is shown in equations (17) and (18). The FLCC was programmed in $\mathrm{C}$ programming language for the simulation because it facilitates its implementation in the digital signal processor TMS320F28335 from the Texas Instrument.

\section{SIMULATION AND EXPERIMENTAL RESULTS}

The simulations activities were performed using the MATLAB R2011b simulation package together with the Simulink block sets and fuzzy logic toolbox. The switching frequency of the three-phase two level inverter was set to be
$10 \mathrm{kHz}$, and the direct component of the stator current $\left(i_{d s}^{*}\right)$ was set to be $1.0 \mathrm{pu}$.

The experimental activities are realized with electronic circuits and three-phase IM. Figure 7 shows the experimental setup built during the development phase. The experimental set-up consists of a DSP (Texas Instruments TMS320F28335) connected to a three-phase squirrel cage IM, driven by a 12kVA Semikron three-phase inverter (SKS 32F $\mathrm{B} 6 \mathrm{U}+\mathrm{E} 1 \mathrm{CIF}+\mathrm{B} 6 \mathrm{CI} 12 \mathrm{V06}$ ). The mechanical load is imposed by a Foucault braking system. Conditioning signal boards are necessary to acquire the motor currents and the Dc link voltage from a high level of voltage and current to an appropriate voltage level to be sampled and converted by the internal AD converter.

In order to investigate the effectiveness of the proposed control system and in order to check the closed-loop stability of the complete system, we performed several tests. The simulated scenarios shown in this article covers the following situations: trapezoidal profile reversion, triangular profile reversion and step change in speed reference; the three tests were made with no load. Moreover, we made a step change in the motor load (from 0 to $1.0 \mathrm{pu}$ and from 0 to $0.5 \mathrm{pu}$ ) at forty percent of rated speed. The parameters of the three-phase IM considered are given in Table II.

Figure 8 shows the response of the rotor angular speed when

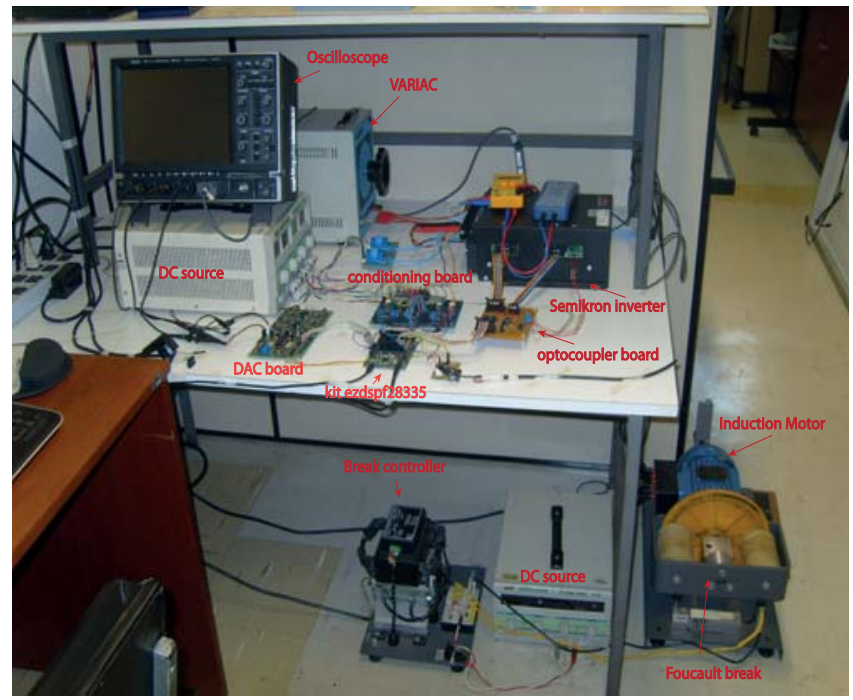

Fig. 7. Experimental set-up showing the induction motor, the Foucault break and the driven set. 


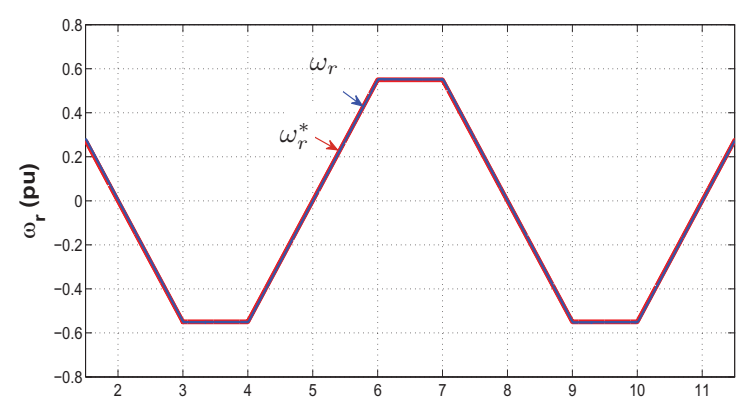

Fig. 8. Simulation response of the rotor angular speed when trapezoidal profile reversion was applied with no load.

a trapezoidal profile reversion was applied to the motor with no load. In this test, the rotor speed tracked the reference as expected. Similar behavior is observed in the experimental test as is shown in Figure 9. Although with some oscillations, the rotor angular speed tracked the reference speed very closely and it was able to follow the rotor speed within $2 \%$ accuracy most of the time.

Figure 10 shows the response of the rotor angular speed when triangular profile reversion was applied to the motor. This test was made with no load too; the rotor speed tracked the triangular profile reference as expected. Similar behavior is observed in the experimental test as is shown in Figure 11.

Figure 12 and Figure 13 show the simulation and experimental results of the rotor angular speed $\omega_{r}$ when a step change is imposed in the reference speed from 0.3 pu to $-0.3 \mathrm{pu}$ with no load. The rotor angular speed achieves the reference speed at approximately 0.7 seconds.

Figure 14 and Figure 15 show the simulation and experimental results of the current components when the step change in the motor load is applied (from 0 to $1.0 \mathrm{pu}$ ). The quadrature-axis component of the stator current takes an increment to maintain the load. Also, it is possible to observe a constant behavior of the direct-axis component of the stator current when load is applied; it shows the decoupled behavior of the DVC method with the proposed FLCC controller.

Finally, Figure 16 and Figure 17 show the simulation and experimental results of the current components and rotor angular speed when the step change in the motor load is applied (from 0 to $0.5 \mathrm{pu}$ ). The behavior of the quadrature components of the stator currents is as expected. When the load is applied the speed is maintained stable with a small overshoot when the load is retreated. All test results show a good performance of the proposed DVC method with the proposed FLCC controller.

\section{CONCLUSION}

In this paper, we presented the direct vector control method with FLCC controller for the three-phase IM. The proposed controller substitutes both PI current controllers present in the conventional DVC method. The FLCC calculates the reference quadrature components of the stator voltage vector in the rotor-flux-oriented reference frame. The direct-axis component of the stator voltage vector is a linear combination

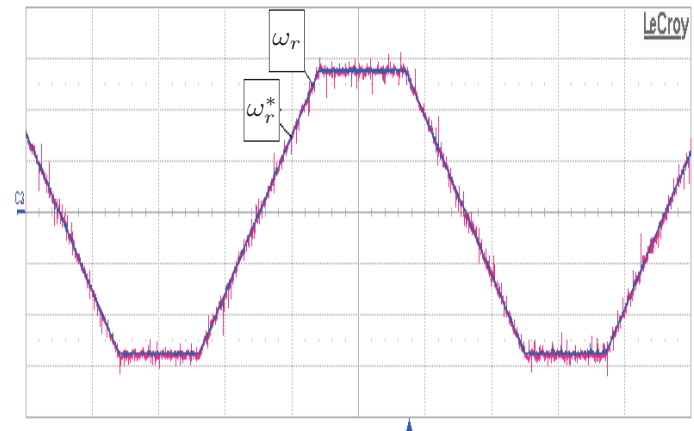

Fig. 9. Experimental response of the rotor angular speed when trapezoidal profile reversion $(0.55 \mathrm{pu}$ to $-0.55 \mathrm{pu})$ was applied with no load $(0.2 \mathrm{pu} / \mathrm{div})$.

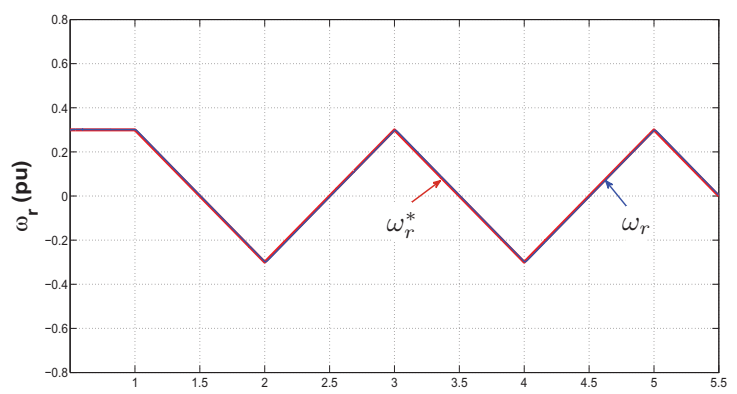

Fig. 10. Simulation Response of the rotor angular speed when triangular profile reversion was applied with no load.

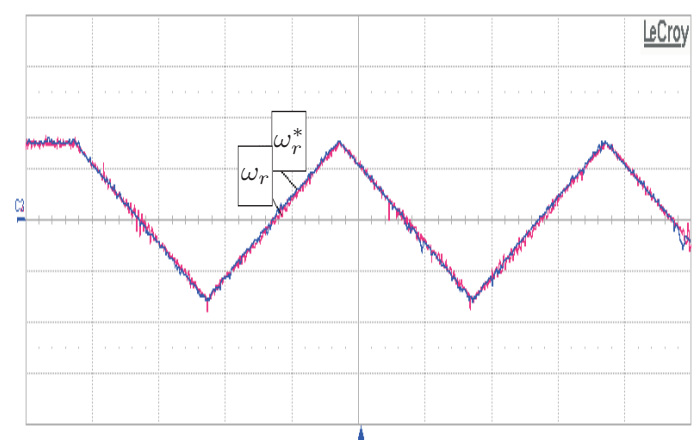

Fig. 11. Experimental response of the rotor angular speed when triangular profile reversion was applied with no load ( $0.2 \mathrm{pu} / \mathrm{div})$.

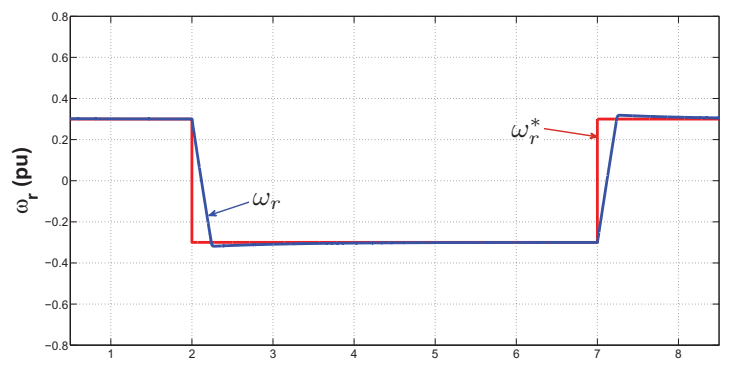

Fig. 12. Simulation response of the rotor angular speed when step change in the speed reference was applied with no load. 


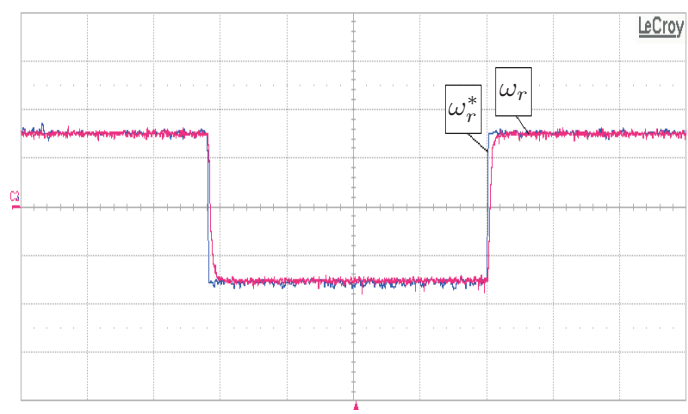

Fig. 13. Experimental response of the rotor angular speed when step change in the speed reference was applied with no load ( $0.2 \mathrm{pu} / \mathrm{div})$.

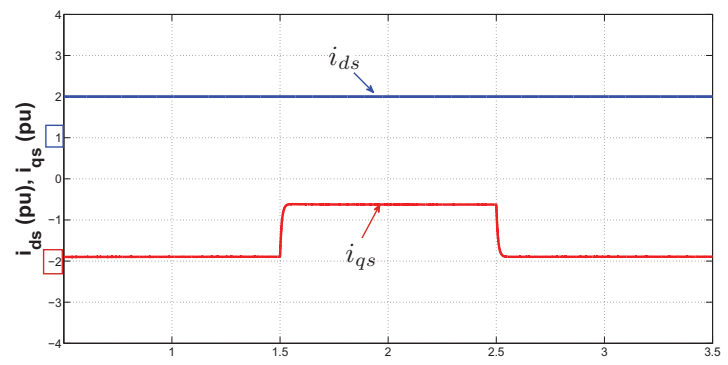

Fig. 14. Simulation response of the quadrature components of the stator currents $\left(i_{d s}, i_{q s}\right)$ in the rotor-flux-oriented reference frame when the rated load was applied.

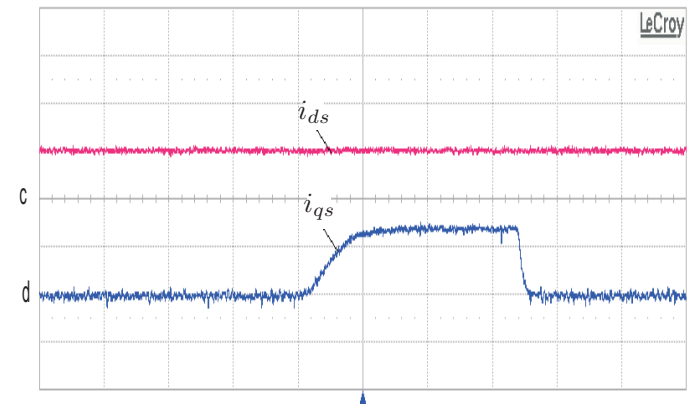

Fig. 15. Experimental response of the quadrature components of the stator currents $\left(i_{d s}, i_{q s}\right)$ in the rotor-flux-oriented reference frame when the rated load was applied ( $\mathrm{C} 2$ and $\mathrm{C} 3 \rightarrow 0.5 \mathrm{pu} / \mathrm{div})$.

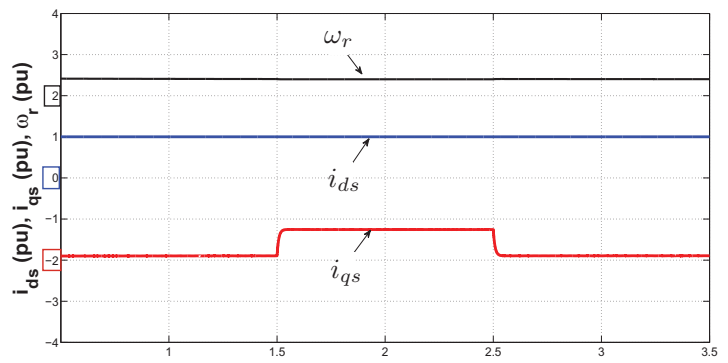

Fig. 16. Simulation response of the rotor angular speed and quadrature components of the stator currents $\left(i_{d s}, i_{q s}\right)$ when the 0.5 $\mathrm{pu}$ of the rated load was applied and when the speed is constant at 0.4 pu.

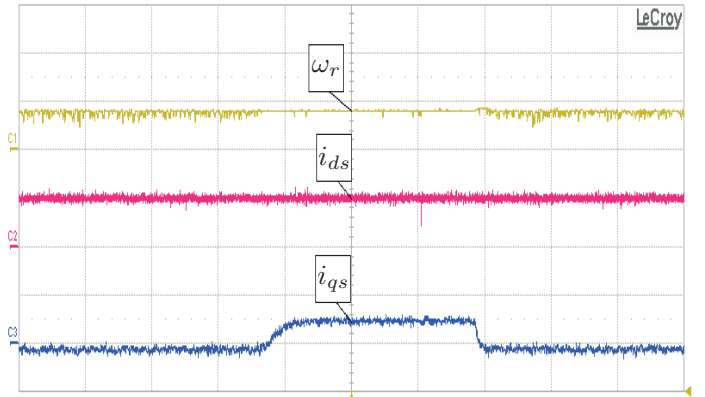

Fig. 17. Experimental response of the rotor angular speed and quadrature components of the stator currents $\left(i_{d s}, i_{q s}\right)$ when the 0.5 $\mathrm{pu}$ of the rated load was applied and when the speed is constant at 0.4 pu ( $\mathrm{C} 1$ and $\mathrm{C} 3 \rightarrow 0.5 \mathrm{pu} / \mathrm{div}$; $\mathrm{C} 2 \rightarrow 1 \mathrm{pu} / \mathrm{div})$.

TABLE II

Induction Motor Parameters

\begin{tabular}{lc}
\hline Rated voltage $(\mathrm{V})$ & $220 / 60 \mathrm{~Hz}$ \\
\hline Rated Power $(\mathrm{HP})$ & 1.5 \\
\hline Rated Torque $(\mathrm{Nm})$ & 6.1 \\
\hline Rated Speed $(\mathrm{rad} / \mathrm{s})$ & 180.12 \\
\hline$R_{s}, R_{r}(\Omega)$ & $5.56,4.25$ \\
\hline$L_{s}, L_{r}(\mathrm{H})$ & $0.309,0.309$ \\
\hline$L_{m}(\mathrm{H})$ & 0.296 \\
\hline$J\left(K_{g} m^{2}\right)$ & 0.02 \\
\hline $\mathrm{P}($ pole pairs $)$ & 2 \\
\hline
\end{tabular}

of the FLCC inputs. Also, the quadrature component of the stator voltage vector use the similar linear combination but with interchanged parameter order, being it not necessary other different parameters values. The rule base for the proposed FLCC controller is defined as a function of the stator current error components. Constant switching frequency and low current ripple were obtained using the space vector modulation technique. Numerical simulations and experimental test have been carried out at different operating conditions. They show decoupling current control and low current ripple. These results show that the proposed DVC scheme with FLCC controller achieve a good performance as expected.

\section{ACKNOWLEDGEMENT}

The authors are grateful to CAPES and FAPESP for the financial support for this research.

\section{REFERENCES}

[1] F. Blaschke. The principle of field orientation as applied to the new transvector closed-loop control system for rotating field machines. Siemens Review, 39(no 5):pp. 217-220, May 1972.

[2] T. Takagi and M. Sugeno. Fuzzy identification of systems and its applications to modeling and control. IEEE transactions on systems, man, and cybernetics, 14(no. 1):pp. 116-132, Jan/Feb 1985.

[3] E. H. Mamdani. Application of fuzzy logic algorithms for control of simple dynamic plant. IEEE Proceedings of the Institution of Electrical Engineers, 121(no. 12):pp 1585-1588, 1974. 
[4] T. Yamakawa. Fuzzy controller hardware system. In Proceedings of 2nd IFSA Congress, pages pp. 827-830, 1987.

[5] F. Lima, W. Kaiser, I. Nunes da Silva, and A.A. de Oliveira. Speed neuro-fuzzy estimator applied to sensorless induction motor control. Latin America Transactions, IEEE (Revista IEEE America Latina), 10(5):2065 -2073, sept. 2012.

[6] M. Suetake, I. N. da Silva, and A. Goedtel. Sistema fuzzy compacto embarcado em dsp e sua aplicao para controle v/f de motores de induo. Controle \& Automao Sociedade Brasileira de Automatica, 21:245 - 259, 062010.

[7] V. Chitra and R. S. Prabhakar. Induction motor speed control using fuzzy logic controller. In World Academy of Science, Engineering and Technology, 2006.

[8] B. Heber, L. Xu, and Y. Tang. Fuzzy logic enhanced speed control of an indirect field-oriented induction machine drive. Power Electronics, IEEE Transactions on, 12(5):772-778, sep 1997.

[9] L. Hakju, L. Jaedo, and S. Sejin. Approach to fuzzy control of an indirect field-oriented induction motor drives. In Industrial Electronics, 2001. Proceedings. ISIE 2001. IEEE International Symposium on, volume 2, pages $1119-1123$ vol.2, 2001.

[10] B.M. Badr, A.M. Eltamaly, and A.I. Alolah. Fuzzy controller for three phases induction motor drives. In Vehicle Power and Propulsion Conference (VPPC), 2010 IEEE, pages $1-6$, sept. 2010.

[11] A. Mechernene, M. Zerikat, and S. Chekroun. Indirect field oriented adaptive control of induction motor based on neuro-fuzzy controller. In Control Automation (MED), 2010 18th Mediterranean Conference on, pages 1109 1114 , june 2010.

[12] T.S. Radwan, M.N. Uddin, and M.A. Rahman. A new and simple structure of fuzzy logic based indirect field oriented control of induction motor drives. In Power Electronics Specialists Conference, 2004. PESC 04. 2004 IEEE 35th Annual, volume 5, pages 3290 - 3294 Vol.5, june 2004.

[13] M. R. Douiri, M. Cherkaoui, and A. Essadki. Genetic algorithms based fuzzy speed controllers for indirect field oriented control of induction motor drive. International Journal of Circuits, Systems and Signal Processing, 6(no. 1):pp. 21-28, 2012.

[14] F. Ashrafzadeh, E.P. Nowicki, and J.C. Salmon. A selforganizing and self-tuning fuzzy logic controller for field oriented control of induction motor drives. In Industry Applications Conference, 1995. Thirtieth IAS Annual Meeting, IAS '95., Conference Record of the 1995 IEEE, volume 2, pages 1656-1662 vol.2, oct 1995.

[15] E. Cerruto, A. Consoli, A. Raciti, and A. Testa. Fuzzy adaptive vector control of induction motor drives. Power Electronics, IEEE Transactions on, 12(6):1028 -1040, nov 1997.

[16] F. Profumo, G. Griva, and V. Donescu. Self tuning fuzzy logic current control for high performance induction motor drives. In Industrial Electronics Society, 1998. IECON '98. Proceedings of the 24th Annual Conference of the IEEE, volume 3, pages $1871-1876$ vol.3, aug-4 sep 1998.

[17] D. Dubois, H. Prade, and R. (Eds.) Yager. Fuzzy Sets for Intelligent Systems. Morgan Kaufmann Publishers; 1st edition (August 1993), 1993.

[18] P. Vas. Sensorless vector and Direct Torque Control. Oxford University Press, 1998.

[19] N.P. Quang and J.A. Dittrich. Vector Control of ThreePhase AC Machines. Springer, 2008.

[20] M. Bertoluzzo, G. Buja, and R. Menis. A direct torque control scheme for induction motor drives using the current model flux estimation. Diagnostics for Electric Machines, Power Electronics and Drives, 2007. SDEMPED 2007. IEEE International Symposium on, pages $185-190$, sept. 2007.

[21] J. Hu and B. Wu. New integration algorithms for estimating motor flux over a wide speed range. Power Electronics, IEEE Transactions on, 13(5):969 -977, sep 1998.

[22] A.W.F. Silveira, D.A. Andrade, C.A. Bissochi, T.S. Tavares, and L.C.S. Gomes. A comparative study between tree philosophies of stator flux estimation for induction motor drive. In Electric Machines Drives Conference, 2007. IEMDC '07. IEEE International, volume 2, pages $1171-1176$, may 2007.

[23] W. Pedrycz and F. Gomide. Fuzzy Systems Engineering Toward Human-Centric Computing. Wiley-IEEE Press, 2007.

[24] M.M. Gupta and J. Qi. Theory of t-norms and fuzzy inference methods. Fuzzy Sets and Systems, 40(3):431 - 450, 1991.

[25] M.M. Gupta and J. Qi. Design of fuzzy logic controllers based on generalized t-operators. Fuzzy Sets and Systems, 40(3):473 - 489, 1991.

[26] D. Driankov, H. Hellendoorn, and M. Reinfrank. An Introduction to Fuzzy Control. Springer, 2nd. edition, 1996.

[27] S. Sandri and C. Correa. Logica nebulosa. In V Escola de Redes Neurais, pages c073-c090, July 1999.

\section{BIOGRAPHIES}

José Luis Azcue Puma was born in Peru in 1981. He received his college education at Universidad Nacional del Altiplano in Peru, and received his bachelor degree in Electronics Engineering in 2004. He received his Master degree in Electrical Engineering in 2010 from University of Campinas (UNICAMP) in Brazil. He is currently pursuing his Ph.D. studies at School of Electrical and Computer Engineering at UNICAMP. His primary areas of interest are electrical machines, ac drives, power electronics, intelligent electrical drives, fuzzy controllers and fuzzy systems. Mr. Azcue is student member of IEEE and member of Industrial Electronics Society of IEEE.

Alfeu J. Sguarezi Filho received his bachelor degree in Electrical Engineering from Faculdade Área 1, his Master degree and his $\mathrm{Ph}$. D. degree from Campinas University in Brazil, respectively in 2005, 2007 and 2010. He was working as researcher at Campinas University by FAPESP pos-doctoral 
program from 2010 to 2011. Now, he is a professor at Federal University of ABC - UFABC, in Santo André, Brazil, teaching in the areas of Electrical Machines, Power Electronics and Electrical Drives. His research interests are machine drives, doubly-fed induction generators, power control, and electrical power systems.

Ernesto Ruppert Filho received his bachelor degree in Electrical Engineering and his Master and $\mathrm{PhD}$ degrees from Campinas University in Brazil, respectively in 1971, 1974 and 1983. From 1972 to 1978 he had been working at Electrical and Computer Engineering School of Campinas University as an Assistance Professor in the Electromechanical Energy Conversion area, from 1979 to 1983 he had been working for General Electric in Brazil designing large induction and synchronous motors and working as an Application Engineer dedicated to large motors and generators, from 1983 to 1989 he had been working for Vigesa Heavy Equipments in Brazil designig very large hydrogenerators and also performing commissionig testes in some hydro power plants in Brazil. From 1989 to 1992 he runned his own company dealing with electrical installations and from 1992 up to now he is working as Full Professor at the Electrical and Computer Engineering School of Campinas University, in Campinas, Brazil, researching and teaching in the areas of Electrical Machines, Power Electronics, Drives and Electrical Power Systems. 